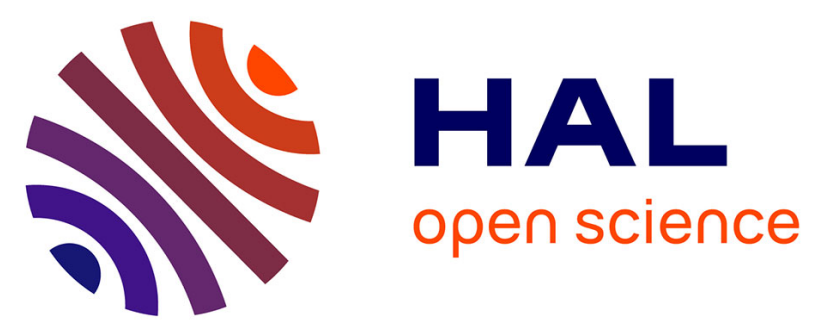

\title{
Characterization of liposome-containing SPIONs conjugated with anti-CD20 developed as a novel theranostic agent for central nervous system lymphoma
}

S. Saesoo, S. Sathornsumetee, P. Anekwiang, C. Treetidnipa, P. Thuwajit, S. Bunthot, W. Maneeprakorn, Lionel Maurizi, H. Hofmann, Ruktanonchai Uracha Rungsardthong, et al.

\section{To cite this version:}

S. Saesoo, S. Sathornsumetee, P. Anekwiang, C. Treetidnipa, P. Thuwajit, et al.. Characterization of liposome-containing SPIONs conjugated with anti-CD20 developed as a novel theranostic agent for central nervous system lymphoma. Colloids and Surfaces B: Biointerfaces, 2018, 161, pp.497-507. 10.1016/j.colsurfb.2017.11.003 . hal-02163452

\section{HAL Id: hal-02163452 https://hal.science/hal-02163452}

Submitted on 14 Mar 2021

HAL is a multi-disciplinary open access archive for the deposit and dissemination of scientific research documents, whether they are published or not. The documents may come from teaching and research institutions in France or abroad, or from public or private research centers.
L'archive ouverte pluridisciplinaire HAL, est destinée au dépôt et à la diffusion de documents scientifiques de niveau recherche, publiés ou non, émanant des établissements d'enseignement et de recherche français ou étrangers, des laboratoires publics ou privés. 
1 Characterization of liposome-containing SPIONs conjugated with anti-CD20 developed as a novel theranostic agent for central nervous system lymphoma

\author{
S. Saesoo $\mathrm{S}^{(1)}$, S. Sathornsumetee ${ }^{(2,5)}$, P. Anekwiang ${ }^{(2)}$, C. Treetidnipa ${ }^{(2)}$, \\ P. Thuwajit (2,4), S. Bunthot ${ }^{(1)}$, W. Maneeprakorn (1), L. Maurizi ${ }^{(6)}$, H. Hofmann (7), \\ Ruktanonchai Uracha Rungsardthong ${ }^{(1)}$, N. Saengkrit ${ }^{(1)}$
}

(1) National Nanotechnology Center (NANOTEC), National Science and Technology

Development Agency (NSTDA), Pathumthani 12120, Thailand

(2) NANOTEC-Mahidol University Center of Excellence in Nanotechnology for Cancer Diagnosis and Treatment and Departments of (3) Radiology, (4) Immunology and (5) Medicine, Faculty of Medicine Siriraj Hospital, Mahidol University 2 Wanglang Road, Bangkoknoi, Bangkok 10700, Thailand

(6) Laboratoire Interdisciplinaire Carnot de Bourgogne, UMR 6303 CNRS-Université Bourgogne Franche-Comté, BP 47870, F-21078 Dijon cedex, France

(7) Powder Technology Laboratory, Ecole Polytechnique Fédérale de Lausanne (EPFL), 1015 Lausanne, Switzerland.

\title{
1. Introduction
}

Despite advances in the understanding of genetic and molecular abnormalities relating to cancer, and in development of new therapies, the prognosis of patients with primary central nervous system lymphoma (PCNSL) remains poor when compared to other lymphoma types (median survival 3-5 years) [1]. For immunocompromised patients, such as those with AIDS or in cases of organ transplantation, median survival times are often markedly reduced (typically less than 1 year) [2]. Due to this, and the rising incidence of PCNSL over the past decades there is a need to develop new diagnostic and therapeutic strategies which are applicable to these patients, including the wider population [3]. 
PCNSL accounts for 3-5\% of primary brain tumors in adults, and occurs with an incidence of 5 per 1,000,000 people in developed countries [1]. Most (> 95\%) PCNSL cases are of the diffuse large B-cell type. Genetic abnormalities in PCNSL cells are distinct from those occurring in other lymphomas; this factor may relate to observed differences in prognosis and treatment response [4]. Non-invasive imaging studies such as magnetic resonance imaging (MRI) and positron-emission tomography (PET) scans can support an initial diagnosis of PCNSL, however confirmation usually requires a stereotactic biopsy. Alternatively, cytology of cerebrospinal fluid, or ocular vitreous, may confirm diagnosis in $20-30 \%$ of patients. Diagnosis of AIDS-associated PCNSL represents an important challenge in clinical practice. Radiographic findings of PCNSL in immunocompromised patients are often indistinguishable from infections, particularly toxoplasmosis. In these cases, biopsies are often deferred until the empiric treatment for toxoplasmosis fails, causing delays in diagnosis. Therefore, non-invasive diagnostic approaches, such as neuroimaging probes, for PCNSL in AIDS patients may hasten diagnosis allowing early treatment. High-dose methotrexate (HD-MTX)-based chemotherapy regimens are the standard treatment for PCNSL [5], and these combined with other chemotherapies (cytarabine, procarbazine, vincristine, or ifosfamide) have been shown to provide superior results in some cases, although the higher toxicity is a serious issue. RTX, a monoclonal antibody against CD20, has demonstrated promising activity as a single agent in PCNSL [6], despite the inherent limitation of such a large molecule in traversing the bloodbrain barrier [7, 8]. Employing nanoparticles as a carrier for RTX may help overcome this challenge, and result in increased efficacy in PCNSL treatment.

The blood-brain barrier represents a major obstacle for drug delivery to the CNS [9, 10]. The use of a small lipophilic carrier, such as a nanoparticle system, may overcome this problem, with nanoparticles allowing for improved drug delivery metrics as well as diagnostic and monitoring capabilities. This emerging molecular platform, "theranostics" [11], employs nanoparticle systems based on liposomes [12], micelles [13], and dendrimers [14] to protect drugs and deliver them to targets in a controlled manner. In addition, they can be decorated with "molecular antennae" such as antibodies or aptamers on their surface to allow target specificity. Imaging probes are an important group of theranostic particles: these can be detected in vivo through various imaging modalities [15]. Superparamagnetic iron oxide nanoparticles (SPIONs) and radioisotopically labelled nanoparticles are common imaging probes detectable by magnetic resonance imaging and positron emission tomography, respectively. Among the various nanoparticle classes available, liposomes have shown real 
promise in the treatment of brain disorders [16-18], having been shown to enhance the delivery of neuroprotective agents to the peri-infarct area in experimental ischemic stroke models [17, 18]. In this study, we fabricated nanoparticles consisting of liposome containing SPIONs decorated with RTX, and subsequently evaluated their imaging and targeting abilities, including therapeutic potency, in a BBB model of PCNSL.

\section{Materials and methods}

\subsection{Materials}

Soybean lecithin (Soya Phosphatidylcholin; PC) was purchased from Degussa (Hamburg, Germany). 1,2-Distearoyl-sn-glycero-3-phosphoethanolamine-N[amino(polythylene glycol 2000)] (DSPEG-PE), and 1,2-dioleoyl-sn-glycero-3phosphoethanolamine-N-[4-(p-maleimidophenyl)butyramide] (MPB-PE, linker) were purchased from Avanti Polar Lipids, Inc (Alabama, USA). Cholesterol was also obtained from Avanti Polar Lipids, Inc (Alabama, USA). Polysorbate 80 (Tween 80) was obtained from Sigma-Aldrich (Saint Louis, MO, USA). Phosphate buffered saline (pH 7.4) (PBS; containing $137 \mathrm{mM} \mathrm{NaCl}, 2.7 \mathrm{mM} \mathrm{KCl}, 10 \mathrm{mM} \mathrm{Na} 2 \mathrm{HPO}_{4} ; 2 \mathrm{mM} \mathrm{KH}_{2} \mathrm{PO}_{4}$ ), and Triton X-100 were obtained from Merck (Merck Millipore, Darmstadt, Germany). Anti-CD20 (RTX) was purchased from Roche (Basel, Switzerland). Roswell Park Memorial Institute media (RPMI 1640) was from GIBCO Invitrogen (New York, USA). Fetal bovine serum (FBS) was obtained from Biochrom AG (Berlin, Germany). Trypsin-EDTA, L-glutamine, penicillin G sodium, streptomicin sulfate, and amphotericin B were obtained from Invitrogen Corp. (New York, USA). MTT [3-(4,5-Dimethylthiazol-2-yl)-2,5-diphenyltetrazolium bromide] was purchased from GIBCO Invitrogen (NY, USA). Dimethylsulfoxide (DMSO) was procured from SigmaAldrich, Inc, (Dorset, UK). The Annexin V-FITC Apoptosis Detection Kit was obtained from NeXins Research BV (Rotterdam, the Netherlands). Distilled water was generated using an ELGA system (PureLab Ultra, Illinois, USA). Z138C and Granta519 lymphoma cell lines were graciously provided by Dr. Siwanon Jirawatnotai (Bangkok, Thailand). SPIONs-PVA nanoparticles were kindly provided by Prof. Heinrich Hofmann and Dr. Lionel Maurizi (EPFL, Switzerland). These particles were synthesized from maghemite $\left(\gamma-\mathrm{Fe}_{2} \mathrm{O}_{3}\right)$, affording SPIONs having a diameter less than $20 \mathrm{~nm}$. All SPIONs were coated with PVA (Polyvinyl alcohol) for stabilization [19] and called SPION-PVA.

\subsection{Lymphoma cell cultivation}


Granta and Z138C cell lines were cultured in RPMI 1640 medium. The medium was supplemented with 10\% FBS containing $0.1 \mathrm{mM}$ non-essential amino acids $(100 \mu \mathrm{g} / \mathrm{ml} \mathrm{L}$ glutamine, $100 \mu \mathrm{g} / \mathrm{ml}$ streptomycin and $100 \mathrm{U} / \mathrm{ml}$ penicillin). Cells were grown and propagated in $75 \mathrm{ml} \mathrm{T}$-flasks, and incubated at $37^{\circ} \mathrm{C}$ in a humidified atmosphere containing $5 \% \mathrm{CO}_{2}$. The medium was changed every other day.

\subsection{Preparation of liposomes and conjugation of RTX}

A series of liposome nanoparticles were prepared by conventional thin film hydration, which involved the mixing of PC, DSPEG-PE, Tween 80 and MPB-PE (linker) in various proportions, as indicated in Table 1. Each mixture was then dissolved in chloroform-diethyl ether $(3: 1 \mathrm{v} / \mathrm{v}, 10 \mathrm{ml})$, and upon solvent removal by rotary evaporation at $25^{\circ} \mathrm{C}$ under $50-100$ $\mathrm{kg} / \mathrm{cm}^{2}$ nitrogen flow thin lipid films were obtained. After drying, lipid films were rehydrated with $0.2 \mathrm{mg}_{\mathrm{Fe}} / \mathrm{ml}$ of SPION-PVA dissolved in PBS ( $\mathrm{pH} 7.4$ ), and re-suspended with shaking at room temperature. Particle sizes of all liposome samples were reduced using a discontinuous extruder (Liposo-Fast ${ }^{\mathrm{TM}}$-10, Avestin Inc, Ottawa, Canada) operating at 200 bar pressure over 15-20 cycles, through a $200 \mathrm{~nm}$ pore size polypropylene membrane (Millipore $\mathrm{GmbH}$, Eschborn, Germany). The SPIONs-PVA loaded liposomes were purified by centrifugation (TomyMX-301, Tokyo, Japan) at 10,000 rpm for $30 \mathrm{~min}$, prior to collection. The obtained pellets were re-suspended in PBS ( $\mathrm{pH}$ 7.4) buffer for measuring of SPION entrapment. Additionally, in order to obtain an optimized formulation for BBB delivery, the following liposome series were initially prepared: liposome (Lip), Lip/PEG, Lip/Tween80, Lip/PEG/Tween80, Lip/PEG/Tween80 and Lip/PEG/Tween80/RTX.

Immobilization of RTX was performed via chemical conjugation. Thiolated RTX was firstly prepared by mixing RTX with 2-iminothiolane at $25^{\circ} \mathrm{C}$ for $30 \mathrm{~min}$. The conjugation of RTX and liposomes was achieved via the coupling of thiolated RTX and MPB-PE onto the liposome surface. This required gradual addition of MPB-PE-liposomes into the freshly prepared thiolated RTX, followed by incubation of the solution at $4{ }^{\circ} \mathrm{C}$ overnight under nitrogen atmosphere, with continuous stirring. The resultant RTX conjugated liposomes were purified by ultracentrifugal sedimentation at $60,000 \mathrm{rpm}$ for $90 \mathrm{~min}$, and the obtained pellets were resuspended and washed twice with PBS buffer ( $\mathrm{pH}$ 7.4).

\subsection{Morphology and physicochemical characterization of liposomes}


The morphology of liposomes was investigated using transmission electron microscopy (TEM). Samples were prepared by placing $5 \mu 1$ of liposome solution onto a 200-mesh carbon copper grid (EMS Equipment, Berks, UK). After $10 \mathrm{~min}$, the droplet was removed from the edge of the grid using filter paper. Samples were dried by standing at room temperature prior to imaging: TEM (model JEM 2010; JEOL, Peabody, MA) accelerating voltage $120 \mathrm{KV}, 50 \mathrm{~K}$ magnification.

Hydrodynamic diameter, polydispersity index (PDI) and zeta potential of liposomes were determined by dynamic light scattering (DLS) (NanoZS4700 nanoseries, Malvern Instruments, Malvern, UK). All samples were diluted with $1 \mathrm{ml}$ of filtered distilled water prior to measurements being taken to eliminate viscosity effects caused by the ingredients. Hydrodynamic diameter (based on volume measurement), PDI and zeta potential were obtained from the average of three measurements at $25^{\circ} \mathrm{C}$. The refractive indices of liposomes and water were set at 1.42 and 1.33 , respectively.

\subsection{Determination of SPIONs-PVA encapsulation}

The encapsulation of SPIONs-PVA within liposomes was quantified using the Prussian Blue assay, where samples were diluted for preparation of a calibration curve (at least 3 serial

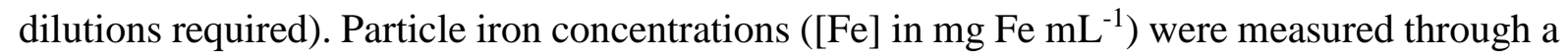
colorimetric assay. SPIONs-PVA were first digested by incubation overnight with an equal volume of $6 \mathrm{M} \mathrm{HCl}$. Then, $25 \mu \mathrm{l}$ of digested particles was mixed with $50 \mu 1$ of $5 \% \mathrm{w} / \mathrm{v}$ $\mathrm{K}_{4} \mathrm{Fe}(\mathrm{CN}) \mathrm{H}_{2} \mathrm{O}$ in water (freshly prepared and covered with aluminium foil). The sample was then shaken continuously for $15 \mathrm{~min}$, followed by measurement of the iron content, which measured from the reaction between $\mathrm{K}_{4}\left[\mathrm{Fe}(\mathrm{CN})_{6}\right]$ and $\mathrm{Fe}^{3+}$ to give an intense blue product (Prussian blue, $\mathrm{Fe}_{4}\left[\mathrm{Fe}(\mathrm{CN})_{6}\right]_{3}$ ) whose optical density was measured at $690 \mathrm{~nm}$ using a microplate spectrophotometer (SpectraMAX2, Molecular Devices GmbH, CA, USA). The encapsulation efficiency was calculated using the equation below.

$$
\% E E=\frac{\text { Total amount of determined SPION }}{\text { Initial amount of SPION loading }} \times 100
$$

\subsection{MTT assay}

To evaluate the toxicity of SPIONs-PVA loaded liposomes, cells were plated in 96well plates, each containing $90 \mu \mathrm{l}$ of RPMI with $10 \%$ fetal bovine serum at a density of 8,000 
cells/well. When the cultures had reached confluency (typically $24 \mathrm{~h}$ after plating) they were exposed to SPIONs-PVA loaded liposomes at SPIONs-PVA concentrations of 0.0005, 0.001, $0.0025,0.005,0.01$ or $0.02 \mathrm{mg}_{\mathrm{Fe}} / \mathrm{ml}$. The treated cells were then incubated for $24 \mathrm{~h}$ at $37^{\circ} \mathrm{C}$ in a $\mathrm{CO}_{2}$ atmosphere. After washing twice with PBS (pH 7.4), $25 \mu \mathrm{l}$ of MTT solution was added into each well, followed by further incubation $(4 \mathrm{~h})$. The medium was then removed and replaced with $100 \mu \mathrm{l}$ of dimethylsulfoxide, followed by further incubation for $30 \mathrm{~min}$ at $37^{\circ} \mathrm{C}$. Following this, the absorbance of the colored solution was measured at $550 \mathrm{~nm}$ using a microplate reader (SpectroMAX, California, US), and the percentage cell viability was calculated using equation and compared with that of the control.

$$
\% \text { Cell survival }=\frac{\left(A b_{550} \text { sample }-A b_{550} \text { control }\right)}{A b_{550} \text { control }} \times 100
$$

$$
\text { where } A b_{550}=\text { absorbance value at } 550 \mathrm{~nm}
$$

\subsection{Stability of liposomes}

Liposome samples were stored in PBS ( $\mathrm{pH} 7.4$ ) buffer at $4^{\circ} \mathrm{C}$, and $25^{\circ} \mathrm{C}$ for prolonged periods to gauge their stability. Samples were taken periodically at intervals of 1,3 and 4 months and liposome stability monitored using particle diameter, polydispersity index (PDI) and zeta potential measurements. Each measurement was performed in triplicate, and expressed as an average value.

\subsection{Magnetization analysis by VSM}

The magnetic properties of SPIONs, SPIONs-PVA and SPIONs-PVA loaded into Lip, Lip/PEG, Lip/Tween80 and Lip/PEG/Tween80/linker liposomes were assessed using vibrating sample magnetometry (VSM, LakeShore Model 7404, USA). For this, all samples were freezedried in liquid nitrogen and lyophilized under vacuum. The magnetic field was applied at 10 kOe in all measurements.

\subsection{Cellular uptake of liposomes}

Internalization of liposomes was monitored by confocal laser scanning microscopy (CLSM), and flow cytometry. To monitor liposome uptake, Lip/PEG-PE and Lip/PEGPE/RTX were labeled with Dil dye tracer (Invitrogen, Paisley, UK) at a ratio of 1:1000 v/v. Granta and Z138C cells $\left(1 \times 10^{6}\right.$ cells $)$ were seeded onto sterilized glass coverslips and allowed 
to adhere overnight in a 6-well plate. At transfection, Dil labeled liposomes were added to the cells at a concentration of $0.4 \mathrm{mg} / \mathrm{ml}$, which corresponds to the $\mathrm{IC}_{20}$ value indicating $80 \%$ cell viability. For CLSM, cell and liposome particles were incubated together for $2 \mathrm{~h}$ at $37^{\circ} \mathrm{C}$ under an atmosphere of $5 \% \mathrm{CO}_{2}$. Cells were then washed twice with PBS (pH 7.4), fixed with $4 \%$ w/v paraformaldehyde for $10 \mathrm{~min}$, and then twice washed again with PBS (pH 7.4). For cellular DNA staining, Hoechst dye (Molecular Probes, OR, USA) was diluted in PBS (pH 7.4) buffer at a ratio of $1: 1500 \mathrm{v} / \mathrm{v}$, then incubated with the cells for $10 \mathrm{~min}$. Cells were washed twice with PBS pH 7.4 after staining then observed under confocal microscope. Images were acquired using a laser scanning confocal microscope (Nikon, ECLIPSE Ti-Clsi4 Laser Unit, Japan), using the 60 objective lane. SPIONs-PVA detection was achieved by reflecting laser scanning, with laser excitation at $488 \mathrm{~nm}$.

Flow cytometry was employed to quantify cell internalization of liposomes. Cells were cultivated in 6-well plates until growth levels reached $80 \%$ confluence. After washing with PBS, cells were incubated with Dil-labeled SPION-PVA loaded liposomes (phosphatidyl choline: Dil 1:500 w/w) at a concentration corresponding to the $\mathrm{IC}_{20}$ value. Cellular internalization of liposomes was quantified with time: after incubation for $30 \mathrm{~min}, 1,2$ and $4 \mathrm{~h}$ unbound liposomes were removed by washing three times with PBS. At each time point, internalization signals were analyzed using a flow cytometer (BD FACS Calibur ${ }^{\mathrm{TM}}$, BD biosciences, CA, USA) at excitation and emission wavelengths of 488 and $600 \mathrm{~nm}$, respectively.

\subsection{Apoptosis assay}

Cells treated with liposomes were double stained with AnnexinV-FITC (AV-FITC) and propidium iodide (PI) to detect apoptotic, and necrotic cells. AV-FITC/PI co-labeling was performed according to the standard protocol as recommended by the manufacturer (BD Pharmingen $^{\mathrm{TM}}$, BD Biosciences, San Jose, CA, USA). Cells were seeded in a 6-well plate at a density of $1 \times 10^{6}$ cells/well, and were allowed to attach for $24 \mathrm{~h}$. After medium refreshment, cells were exposed to either RTX, Lip, Lip/PEG-PE/SPIONs-PVA, Lip/PEGPE/Tween80/SPIONs-PVA or Lip/PEG-PE/Tween80/SPIONs-PVA/RTX at a concentration corresponding to the $\mathrm{IC}_{20}$ for $24 \mathrm{~h}$ at $37^{\circ} \mathrm{C}$. Cells were then detached using trypsin-EDTA solution, re-suspended in fresh medium, and centrifuged at 1,000 rpm for $5 \mathrm{~min}$. The obtained pellets were re-suspended in PBS ( $\mathrm{pH} 7.4)$, centrifuged for a further $5 \mathrm{~min}$ (1,000 rpm), and then collected and re-suspended in AnnexinV binding buffer. All samples were stained with 5 
$\mu \mathrm{l}$ of AV-FITC and $10 \mu \mathrm{l}$ of PI, and then incubated for $15 \mathrm{~min}$ in the dark at $25^{\circ} \mathrm{C}$. After addition of $250 \mu \mathrm{l}$ of AnnexinV binding buffer to each, cells were analyzed using flow cytometry (BDFACS Calibur ${ }^{\mathrm{TM}}$, BD biosciences, San Jose CA, USA). The flow cytometer was equipped with filters capable of detecting PI at excitation/emission wavelengths of 520/570 nm, while FITC was detectable at excitation/emission wavelengths of 485/535 nm. Results are presented in a dot plot of AV-FITC versus PI with quadrant gating. The percentage apoptosis in cells was determined using the FACSDiva software package.

\subsection{In vitro model BBB of PCNSL for permeability and therapeutic testing}

Permeability of the BBB can be gauged by measuring the transendothelial electrical resistance (TEER), which affords a direct relation to its structural integrity. An in vitro coculture model of BBB was set up according to protocol of Imamura et al. [20]. For this, bEnd3 cells were seeded onto $0.4 \mu \mathrm{m}$ pore size polyester membrane inserts (density of 20,000 cells/insert) contained in a 12-well plate transwell tray (Corning, NY, USA). The cells were allowed to grow on the membrane for 8 days, with the DMEM medium being changed every 2 days. With this system, the drug targeting, and therapeutic effect, of RTX and liposomes on B cell lymphoma cells was evaluated: for this, Granta cells were seeded at the bottom of the culture dish and were allowed to grow for 4 days. After this time the TEER values were monitored until they reached 140-150 $\Omega . \mathrm{cm}^{2}$ (approximately 7-10 days), after which the model was ready for use in testing. Testing involved loading either free RTX, Lip/PEG/Tween80/SPIONs-PVA or Lip/PEG/Tween80/SPIONs-PVA/RTX into separate apical compartments of the co-culture model, with final concentrations of RTX $(17.5 \mu \mathrm{g} / \mathrm{ml})$ coinciding with that of the $\mathrm{IC}_{50}$ of free RTX against Granta cells.

Determination of RTX concentrations in the membrane model was undertaken at set time points (1, 2, 3, 5, 7 and 24 h) using the PK ELISA Kit (MyBioSource, CA, USA), with harvesting of Granta cells at these times allowing evaluation of therapeutic effects. During the $24 \mathrm{~h}$ period, the TEER value was also monitored using a Millicell ERS-2 Voltohmmeter (Millipore, MA, USA) for analysis of the permeability efficiency.

\section{Results and discussion}

\subsection{Morphology and physicochemical characterization of liposomes and encapsulation} efficiency 
TEM was employed to observe the morphologies of SPIONs-PVA, bare liposomes and SPIONs-PVA loaded liposomes. While all samples were dehydrated for imaging, the nanoparticles could be observed as having discrete spherical shapes (Fig. 1). SPIONs-PVA showed a narrow size distribution $(<20 \mathrm{~nm}$ ) (Fig. 1a). Liposomes fabricated in the absence of added nanoparticles are spherical in shape but show slight deformations (Fig. 1b and c), while SPIONs-PVA loaded liposomes exhibit a more pristine spherical profile as a result of tight cargo packing resulting in size reduction, and enhanced stability, under TEM voltage exposure (Fig. 1d and e).

Average hydrodynamic diameters, PDI and zeta potentials for bare, and SPIONs-PVA loaded liposomes were obtained using DLS, with data summarized in Table 1. In the absence of cargo, the diameters of Lip (control), Lip/PEG, Lip/Tween80, Lip/PEG/Tween80 and Lip/PEG/Tween80/RTX liposomes were $141.9 \pm 1.0 \mathrm{~nm}, 169.9 \pm 11.3 \mathrm{~nm}, 161.0 \pm 12.6 \mathrm{~nm}$, $157.2 \pm 9.1 \mathrm{~nm}$ and $182.0 \pm 6.3 \mathrm{~nm}$, respectively. Consistent with TEM results, loading of SPIONs-PVA induces liposome contraction, an effect perhaps related to strong hydrophilic interactions between liposome phospholipids and the PVA coating of SPIONs, which would underpin their stability under TEM conditions [21]. The PDI index of all liposomes, being in the range of 0.1 to 0.3 , is indicative of homogeneity and narrow size distribution, which is again consistent with findings from TEM. Loading of SPIONs-PVA results in liposome surface charges becoming more negative, with these having zeta potentials ranging from -2.3 to -9.0 $\mathrm{mV}$, depending on liposome composition. This result probably relates to the interaction of the SPIONs-PVA surface with PC in the liposome membrane. Surface modification of liposomes via RTX conjugation also affected their physicochemical properties: the zeta potential of bare liposome (Lip) was $-0.1 \mathrm{mV}$, whereas that of Lip/PEG/Tween80/RTX became more negative $(-7.2 \mathrm{mv})$ (Table 1).

SPIONs-PVA liposome loadings were quantified using the Prussian Blue assay as described in section 2.5. From this data encapsulation efficiencies (\%EE) for each liposome formula were obtained (Table 1). A notable effect resulted from inclusion of Tween 80 into the liposome structure: this resulted in remarkably higher entrapment (higher \%EE) of SPIONsPVA relative to other liposome formulations. It is assumed that Tween80 incorporation into the film helps to promote liposome stability, and prevents egress of SPIONs-PVA during preparation [22].

\subsection{Liposome cytotoxicity}


The toxicity of SPIONs-loaded liposome formulas was analyzed using Z138c as a lymphoma cell model, in order to evaluate their safety. All liposomes showed concentrationdependent cytotoxicity, although no significant effects to cells were evident on exposure to bare SPIONs-PVA (Fig. 2). Liposome solutions having SPIONs-PVA concentrations less than $0.0025 \mathrm{mg} / \mathrm{ml}$ were considered safe, as exposure to these resulted in greater than $80 \%$ cell survival rates. Higher cytotoxicities were found for Tween 80 fabricated liposomes; addition of Tween 80 may enhance cellular uptake via ApoE ligand-mediated endocytosis [23]. However, for these systems cell viabilities are still in the acceptable range although optimization of liposome concentrations needs to be addressed to further their use in theranostic applications.

\subsection{Stability of liposomes}

In this study, we determined the stability of liposomes on storage at $4^{\circ} \mathrm{C}$ and $25^{\circ} \mathrm{C}$. Particle diameter, PDI and zeta potential of Lip, Lip/PEG/Tween20/SPIONs and Lip/PEG/Tween20/SPIONs/RTX were measured periodically (1, 3 and 4 months) after storage (Table 2). In regards to diameter and zeta potential of colloidal liposomes, for both temperatures all formulations were stable for up to 3 months. Liposome stability could be prolonged for a further month at $4^{\circ} \mathrm{C}$, in contrast to results at $25^{\circ} \mathrm{C}$ which show dramatic changes in zeta potential during the $4^{\text {th }}$ month of storage. This would indicate aggregation of liposome particles over time, as reflected by an increase in particle diameter. However, diameter increases, and zeta potential changes are less marked in Tween80 supplemented liposomes, the enhanced stability of these being consistent with previous work highlighting the use of Tween80 as a non-ionic surfactant to improve liposome stability [22].

\subsection{Magnetic property analysis by vibrating scanning magnetometry (VSM)}

Vibrating scanning magnetometry (VSM) was performed to confirm the superparamagnetic properties of SPIONs-loaded liposomes. Figure 3 highlights magnetization curves, and saturation magnetization of SPIONs-PVA $(0.5 \mathrm{mg} / \mathrm{ml})$, and the series of liposomes: Lip, Lip/PEG/SPION-PVA, Lip/PEG/Tween80/SPION-PVA, and Lip/PEG/Tween80/SPIONPVA/RTX. The saturation magnetization values of naked SPIONs were also determined, as a positive control. The hysteresis curves of SPIONs-loaded liposomes showed an absence of remanence, and this, in conjunction with the magnetization on average being zero, indicates that the SPIONs exhibit superparamagnetic behavior. Although the saturated magnetization value of naked SPIONs was found to be $28.9 \mathrm{emu} / \mathrm{g}$, coating with PVA results in a drastic magnetization decrease $(1.5 \mathrm{emu} / \mathrm{g})$. This effect has been noted previously, for example in PVA 
coated magnetite magnetic [24], and silica coated magnetic nanoparticles [25]. For SPIONsPVA loaded liposomes, the saturated magnetization values were in range of 0.2-0.5 emu/g (Fig. $3)$. This magnetization range corresponds to those of SPIONs obtained from maghemite $(\gamma-$ $\mathrm{Fe}_{2} \mathrm{O}_{3}$ ), the values of which are thought to be lower than those from magnetite $\left(\mathrm{Fe}_{3} \mathrm{O}_{4}\right)$ [26] These findings are a preliminary step in the characterization of these systems, however for actual implementation as theranostics further optimization of the magnetization value is necessary.

\subsection{Liposome cellular internalization and uptake}

Cellular uptake, and distribution of liposomes and SPIONs-PVA was monitored by confocal microscopy. Cells were treated with Lip/PEG/Tween80/SPIONs-PVA and Lip/PEG/Tween80/SPIONs-PVA/RTX, according to the protocol described in section 2.9. At $2 \mathrm{~h}$ post incubation, SPIONs-PVA were detectable within cells (as shown in green) by reflecting laser scanning (excitation at $488 \mathrm{~nm}$ ), while liposome nanoparticles appear red due to the presence of Dil (Fig. 4). Z-stack imaging analysis confirmed internalization of the particles within the liposomes (data not shown). Confocal imaging indicated that signal intensities of Lip/PEG/Tween80/SPIONs-PVA/RTX were significantly higher than those of Lip/PEG/Tween80/SPIONs-PVA, both in Z138c and Granta cell lines (Fig. 4a and 4b). These results imply that conjugation of RTX promotes liposome internalization and provides evidence supporting that binding of RTX occurs selectively on CD-20 presenting lymphoma cells.

To confirm targeting of RTX conjugates with CD-20 lymphoma cells, we then monitored the cellular uptake of liposomes quantitatively by flow cytometry. Lip/PEG/Tween80/SPIONs-PVA and Lip/PEG/Tween80/SPIONs-PVA/RTX were incubated with cultured cells, and uptake was monitored at times of $30 \mathrm{~min}, 1$, 2, and $4 \mathrm{~h}$. Histograms obtained from flow cytometry analysis indicate that cellular internalization of liposomes is time-dependent (Fig. 5). While liposome uptake takes place within $0.5 \mathrm{~h}$-post incubation, the signal intensities of Lip/PEG/Tween80/SPIONs-PVA and Lip/PEG/Tween80/SPIONsPVA/RTX were not equal, and were observed to change during the incubation period. In both Granta and Z138c cell lines the signal intensity from Lip/PEG/Tween80/SPIONs-PVA/RTX proved higher than that resulting from Lip/PEG/Tween80/SPIONs-PVA, which confirmed that RTX functions as a specific antibody for selective binding to anti-CD20 receptors in lymphoma cells. 


\subsection{Apoptosis induction by RTX conjugated liposomes}

RTX is a mainstay in therapies for a broad variety of B-cell malignancies [27, 28]. It induces direct apoptosis through binding to CD20 on the surface of lymphoma cells. In order to verify targeting, and therapeutic effects of Lip/PEG/Tween80/SPIONs-PVA/RTX, annexinV-FITC/PI staining was employed to monitor RTX-induced cell death. For this, Granta and Z138c cell lines were incubated with free RTX $(7.9 \mu \mathrm{g} / \mathrm{ml})$, bare liposomes (Lip), Lip/PEG/SPIONs-PVA, Lip/PEG/Tween80/SPIONs-PVA and Lip/PEG/Tween80/SPIONsPVA/RTX (at the $\mathrm{IC}_{20}$ concentration) for $24 \mathrm{~h}$ at $37^{\circ} \mathrm{C}$. Cells were then removed to determine the degree of apoptosis using flow cytometry. In Fig. 6a and 6b, the lower right quadrant shows annexin positive cells (early apoptotic stage) and the upper right quadrant shows annexin and PI positive cells (late stage apoptosis). Lip/PEG/Tween80/SPIONs-PVA/RTX induced apoptosis by a significantly high degree in both Granta and Z138c cells (by $65.4 \%$ and $43.1 \%$, respectively), while free RTX resulted in lower levels of apoptosis induction (18.3\% and 16.7\% in Granta and Z138c cells, respectively). These results not only suggest that RTX exerts therapeutic effects, but also illustrates the effect of liposome conjugation on the efficacy of apoptosis induction. The presence of RTX on the surface of liposomes allows for advantageous binding with the target cells in addition to facilitating its cellular uptake, in line with its role as a therapeutic agent. Notably, treatment of cells with RTX-free liposomes results in less than $10 \%$ apoptosis, suggesting that the carrier itself is relatively benign.

\subsection{Transport of RTX across the BBB model}

In order to demonstrate transportation of our formulated liposome across the $\mathrm{BBB}$, an in vitro $\mathrm{BBB}$ model was established according to a previous protocol [20]. During the investigation (over $24 \mathrm{~h}$ ), TEER values of the cell control were constantly maintained at 140$150 \Omega . \mathrm{cm}^{2}$. After model development, it was loaded with free RTX and Lip/PEG/Tween80/SPIONs-PVA/RTX, and these samples were allowed to pass the cell monolayer for a set time period. The extent of transported RTX was quantified by ELISA measurements at set time points, up to $24 \mathrm{~h}$ post-loading. The results revealed that free RTX is not readily transported through the BBB membrane, although liposomes act as a facile delivery system promoting cross-barrier transport (Fig. 7). Tween 80 may play a crucial role in fabrication of this delivery system: previous work has highlighted its binding with ApoE on bEnd3 endothelial cells [23]. Concentrations of RTX detected across the membrane were timedependent and were consistent with TEER values, except for the period at $5 \mathrm{~h}$ post incubation 
where the level of permeable RTX may have been affected by the charge on the bEnd3 endothelial membrane.

\subsection{Evaluation of drug targeting therapeutic effect}

As the ability of RTX to be transported across the BBB is a major factor dictating its therapeutic effects, the capacity of RTX to target Granta cells was evaluated in the BBB model by analysis of cellular viability. Free RTX and Lip/PEG/Tween80/SPIONs-PVA/RTX were loaded onto the BBB model, at an RTX concentration corresponding to the $\mathrm{IC}_{50}(17.5 \mu \mathrm{g} / \mathrm{ml})$. At $24 \mathrm{~h}$ post incubation, Granta cells located at the basal layer were collected to evaluate cell viability, in comparison with the control. The results shown in Fig. 8 indicate that, during the incubation period, no effects relating to free RTX were observed. In contrast, exposure to RTXconjugated liposomes resulted in noticeable toxic effects after $5 \mathrm{~h}$, with the level of toxicity being time-dependent. This result confirmed that effective delivery of RTX across the BBB requires a delivery system, and accordingly modified liposomes may be considered as an appropriate vehicle for promoting therapeutic effects.

\section{Conclusion}

Diagnosis of primary CNS lymphoma currently relies on pathology derived from a brain biopsy, which carries significant risk. Non-invasive neuroimaging protocols that can accurately distinguish lymphoma from other disorders are urgently needed, particularly in immunocompromised patients. In this study, we developed a new diagnostic nanoparticle platform for CNS lymphoma consisting of SPIONs loaded liposomes conjugated with antiCD20 (RTX). Liposomal RTX may also exhibit activity against CNS lymphoma, although preclinical evaluations of its efficacy are still being investigated.

A previous study has evaluated ferumoxytol (Feraheme), an iron oxide nanoparticle, as an MRI contrast agent for primary CNS lymphoma and CNS inflammatory disorders [29]. From the immunofluorescence and flow cytometric results herein which demonstrate higher specificity of anti-CD20-liposome-SPIONs for detection of lymphoma cells over classically used coated SPIONs, and the ability of anti-CD20-liposome-SPIONs, despite their large size, to cross the blood-brain barrier into lymphoma xenografts, it is possible that conjugation of anti-CD20 as a targeting moiety in the liposome-SPION complex will result in greater specificity for lymphoma detection by MRI than is possible in other contrast agents (such as gadolinium and ferumoxytol). Accordingly, anti-CD20-liposome-SPIONs may serve as a 
400

401

402

403

404

405

406

407

408

409

410

411

412

413

414

415

416

417

418

419

420

421

422

423

424

425

426

427

428

429

430

431

432

433

434

435

436

437

438

439

440

441

442

443

444

445

446

promising theranostic MRI contrast agent for specific detection, and monitoring of CNS lymphoma.

1. Behin, A., et al., Primary brain tumours in adults. The Lancet, 2003. 361(9354): p. 323-331.

2. Subsai, K., et al., Neurological complications in AIDS patients receiving HAART: a 2-year retrospective study. European journal of neurology, 2006. 13(3): p. 233-239.

3. Olson, J.E., et al., The continuing increase in the incidence of primary central nervous system non-Hodgkin lymphoma. Cancer, 2002. 95(7): p. 1504-1510.

4. Tun, H.W., et al., Pathway analysis of primary central nervous system lymphoma. Blood, 2008. 111(6): p. 3200-3210.

5. Batchelor, T. and J.S. Loeffler, Primary CNS lymphoma. Journal of Clinical Oncology, 2006. 24(8): p. 1281-1288.

6. Birnbaum, T., et al., Successful long-term control of lymphomatous meningitis with intraventricular rituximab. Journal of Clinical Neuroscience, 2014. 21(2): p. 356-358.

7. Gerstner, E.R., et al., Long-term outcome in PCNSL patients treated with high-dose methotrexate and deferred radiation. Neurology, 2008. 70(5): p. 401-402.

8. Batchelor, T., et al., Rituximab monotherapy for patients with recurrent primary CNS lymphoma. Neurology, 2011. 76(10): p. 929-930.

9. Bicker, J., et al., Blood-brain barrier models and their relevance for a successful development of CNS drug delivery systems: a review. European Journal of Pharmaceutics and Biopharmaceutics, 2014. 87(3): p. 409-432.

10. Gribkoff, V.K. and L.K. Kaczmarek, The Need for New Approaches in CNS Drug Discovery: Why Drugs Have Failed, and What Can Be Done to Improve Outcomes. Neuropharmacology, 2016.

11. Kreuter, J., Nanoparticulate systems for brain delivery of drugs. Advanced drug delivery reviews, 2001. 47(1): p. 65-81.

12. Al-Jamal, W.T. and K. Kostarelos, Liposomes: from a clinically established drug delivery system to a nanoparticle platform for theranostic nanomedicine. Accounts of chemical research, 2011. 44(10): p. 1094-1104.

13. Chen, H.-P., et al., A novel micelle-forming material used for preparing a theranostic vehicle exhibiting enhanced in vivo therapeutic efficacy. Journal of medicinal chemistry, 2015. 58(9): p. 3704-3719.

14. Luong, D., et al., Polyvalent Folate-Dendrimer-Coated Iron Oxide Theranostic Nanoparticles for Simultaneous Magnetic Resonance Imaging and Precise Cancer Cell Targeting. Biomacromolecules, 2017.

15. Luchetti, A., et al., Monoclonal antibodies conjugated with superparamagnetic iron oxide particles allow magnetic resonance imaging detection of lymphocytes in the mouse brain. Molecular imaging, 2012. 11(2): p. 7290.2011. 00032.

16. Ramos-Cabrer, P. and F. Campos, Liposomes and nanotechnology in drug development: focus on neurological targets. Int J Nanomedicine, 2013. 8: p. 951-960.

17. Adibhatla, R.M., J. Hatcher, and K. Tureyen, CDP-choline liposomes provide significant reduction in infarction over free CDP-choline in stroke. Brain research, 2005. 1058(1): p. 193197.

18. Ramos-Cabrer, P., et al., Serial MRI study of the enhanced therapeutic effects of liposomeencapsulated citicoline in cerebral ischemia. International journal of pharmaceutics, 2011. 405(1): p. 228-233.

19. Strehl, C., et al., Effects of PVA-coated nanoparticles on human Thelper cell activity. Toxicology letters, 2016. 245: p. 52-58. 
20. Imamura, S., et al., The blood-brain barrier permeability of geissoschizine methyl ether in Uncaria hook, a galenical constituent of the traditional Japanese medicine yokukansan. Cellular and molecular neurobiology, 2011. 31(5): p. 787-793.

21. Chastellain, M., et al., Superparamagnetic Silica-Iron Oxide Nanocomposites for Application in Hyperthermia. Advanced Engineering Materials, 2004. 6(4): p. 235-241.

22. Kronberg, B., et al., Preparation and evaluation of sterically stabilized liposomes: colloidal stability, serum stability, macrophage uptake, and toxicity. Journal of pharmaceutical sciences, 1990. 79(8): p. 667-671.

23. Wagner, S., et al., Uptake mechanism of ApoE-modified nanoparticles on brain capillary endothelial cells as a blood-brain barrier model. PloS one, 2012. 7(3): p. e32568.

24. Kayal, S. and R. Ramanujan, Doxorubicin loaded PVA coated iron oxide nanoparticles for targeted drug delivery. Materials Science and Engineering: C, 2010. 30(3): p. 484-490.

25. Rho, W.-Y., et al., Facile synthesis of monodispersed silica-coated magnetic nanoparticles. Journal of Industrial and Engineering Chemistry, 2014. 20(5): p. 2646-2649.

26. Wu, W., et al., Recent progress on magnetic iron oxide nanoparticles: synthesis, surface functional strategies and biomedical applications. Science and technology of advanced materials, 2015. 16(2): p. 023501.

27. Deans, J.P., H. Li, and M.J. Polyak, CD20-mediated apoptosis: signalling through lipid rafts. Immunology, 2002. 107(2): p. 176-182.

28. Taylor, R.P. and M.A. Lindorfer, Analyses of CD20 Monoclonal Antibody-Mediated Tumor Cell Killing Mechanisms: Rational Design of Dosing Strategies. Molecular pharmacology, 2014. 86(5): p. 485-491.

29. Farrell, B.T., et al., Using iron oxide nanoparticles to diagnose CNS inflammatory diseases and PCNSL. Neurology, 2013. 81(3): p. 256-263. 


\section{Fig. 1.}
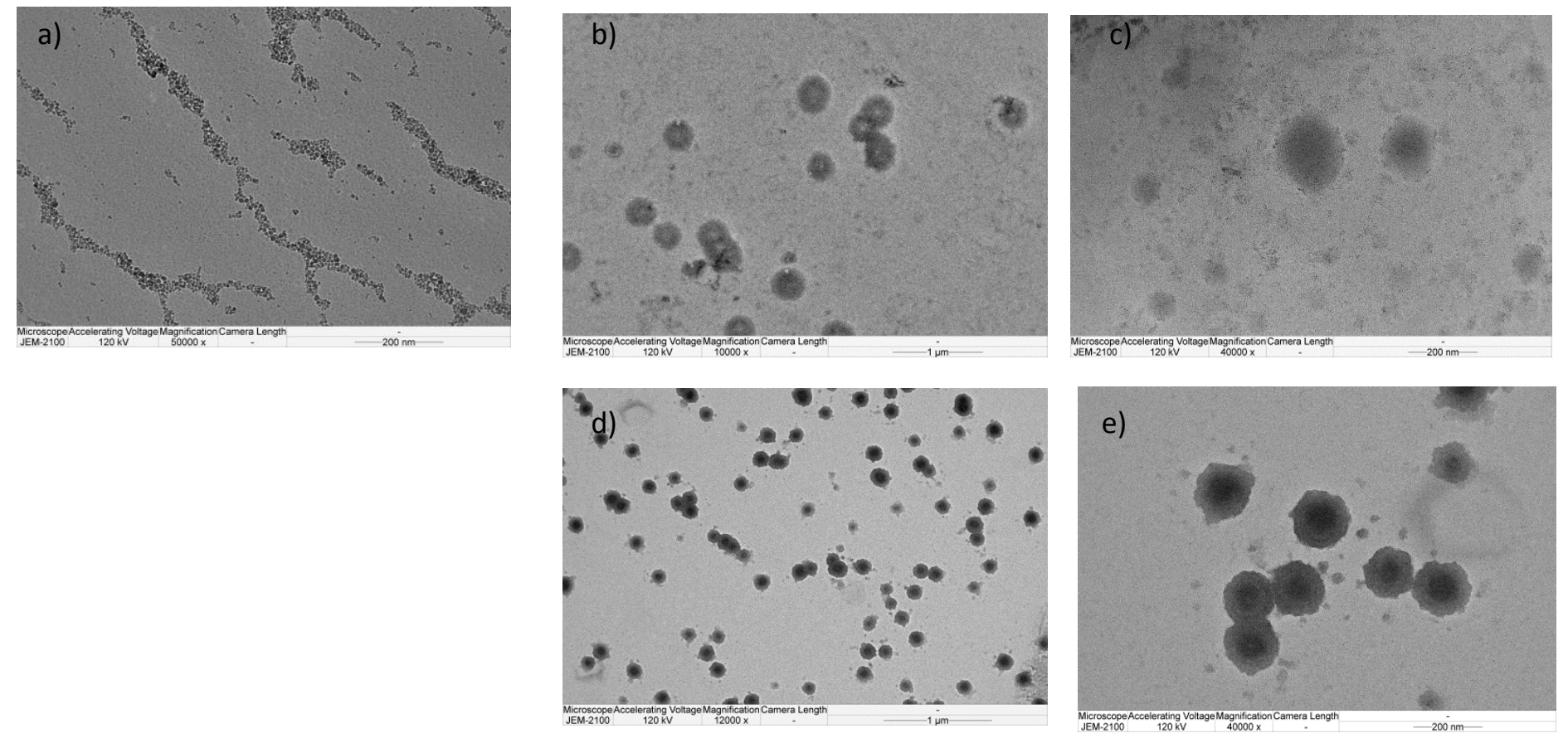

Figure 3. Morphology of liposome was magnified by Transmission Election Microscopy. a) SPIONs-PVA, b) and c) = bare (iposome, d) and e) = SPIONs-PVA loaded liposome at 12,000 and 40,000 magnification, respectively. 


\section{Table 1 Physicochemical characterization of liposomes}

\begin{tabular}{|c|c|c|c|c|c|c|c|c|}
\hline \multirow[b]{2}{*}{ Formulation } & \multirow[b]{2}{*}{ ow/w } & \multicolumn{2}{|c|}{ Size $(\mathrm{nm})$} & \multicolumn{2}{|c|}{ PDI } & \multicolumn{2}{|c|}{ Zeta potential $(\mathrm{mV})$} & \multirow{2}{*}{$\begin{array}{l}\% \text { EE of } \\
\text { SPIONs- } \\
\text { PVA }\end{array}$} \\
\hline & & \begin{tabular}{|c|}
$\begin{array}{c}\text { w/o SPIONs- } \\
\text { PVA }\end{array}$ \\
\end{tabular} & $\begin{array}{c}\text { w/t SPIONs- } \\
\text { PVA }\end{array}$ & $\begin{array}{c}\text { w/o SPIONs- } \\
\text { PVA } \\
\end{array}$ & $\begin{array}{c}\text { w/t SPIONs- } \\
\text { PVA }\end{array}$ & $\begin{array}{c}\text { w/o SPIONs- } \\
\text { PVA }\end{array}$ & $\begin{array}{c}\text { w/t SPIONs- } \\
\text { PVA }\end{array}$ & \\
\hline Lip & & $141.9 \pm 1.0$ & $129.9 \pm 5.6$ & $0.1 \pm 0.1$ & $0.3 \pm 0.0$ & $-0.1 \pm 0.0$ & $-2.3 \pm 0.1$ & $30.0 \pm 4.1$ \\
\hline Lip/PEG & $: 10$ & $169.7 \pm 11.3$ & $140.5 \pm 16.2$ & $0.1 \pm 0.0$ & $0.3 \pm 0.0$ & $-2.3 \pm 0.3$ & $-5.1 \pm 0.7$ & $27.3 \pm 3.3$ \\
\hline Lip/Twee & $: 10$ & $161.0 \pm 12.6$ & $123.8 \pm 19.5$ & $0.2 \pm 0.1$ & $0.3 \pm 0.1$ & $-0.3 \pm 0.0$ & $-2.7 \pm 0.4$ & $41.4 \pm 0.0$ \\
\hline $\begin{array}{l}\text { Lip/PEG/ } \\
\text { Tween80 } \\
\end{array}$ & $: 10: 10$ & $157.2 \pm 9.1$ & $136.4 \pm 4.1$ & $0.2 \pm 0.0$ & $0.2 \pm 0.0$ & $-2.2 \pm 0.2$ & $-5.6 \pm 0.7$ & $45.6 \pm 8.2$ \\
\hline $\begin{array}{l}\text { Lip/PEG/ } \\
\text { Tween80/Rituximab }\end{array}$ & $: 10: 10: 1$ & $182.0 \pm 6.3$ & $158.2 \pm 13.3$ & $0.2 \pm 0.0$ & $0.3 \pm 0.0$ & $-7.2 \pm 0.4$ & $-9.0 \pm 0.1$ & $44.6 \pm 3.4$ \\
\hline
\end{tabular}


Fig. 2. MTT assay of liposome and SPIONs-PVA -loaded liposome

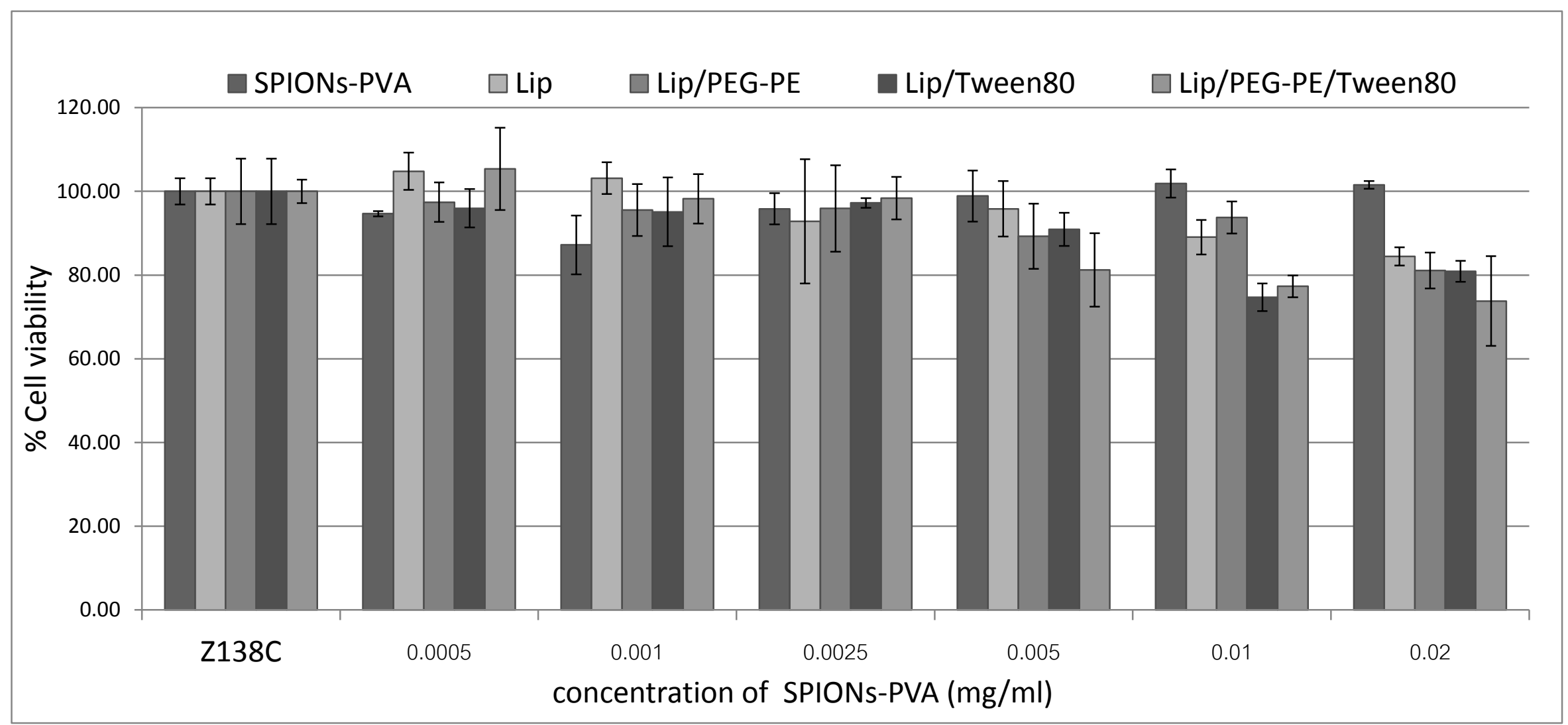




\section{Table 2 stability of liposomes}

\begin{tabular}{|c|c|c|c|c|c|c|}
\hline \multirow[t]{2}{*}{$\begin{array}{l}\text { Storage } \\
\text { period }\end{array}$} & \multicolumn{2}{|c|}{ Lip } & \multicolumn{2}{|c|}{$\begin{array}{c}\text { Lip/PEG/Tween80/SPIONs- } \\
\text { PVA }\end{array}$} & \multicolumn{2}{|c|}{$\begin{array}{c}\text { Lip/PEG/Tween80/SPIONs- } \\
\text { PVA/Rituximab }\end{array}$} \\
\hline & $4^{\circ} \mathrm{C}$ & $25^{\circ} \mathrm{C}$ & $4^{\circ} \mathrm{C}$ & $25^{\circ} \mathrm{C}$ & $4^{\circ} \mathrm{C}$ & $25^{\circ} \mathrm{C}$ \\
\hline \multicolumn{7}{|c|}{ Size $(\mathrm{nm})$} \\
\hline $1 \mathrm{~m}$ & $123.5 \pm 10.1$ & $156.8 \pm 2.7$ & $182.4 \pm 16.3$ & $167.9 \pm 24.5$ & $152.5 \pm 30.0$ & $159.2 \pm 14.7$ \\
\hline $3 \mathrm{~m}$ & $254.6 \pm 8.1$ & $227.1 \pm 1.2$ & $168.1 \pm 7.9$ & $244.7 \pm 6.9$ & $229.4 \pm 5.5$ & $285.7 \pm 12.7$ \\
\hline $4 m$ & $313.0 \pm 16.9$ & $379.7 \pm 6.5$ & $215.0 \pm 19.5$ & $242.0 \pm 1.4$ & $233.3 \pm 8.0$ & $236.4 \pm 5.5$ \\
\hline \multicolumn{7}{|c|}{$\zeta(\mathrm{mV})$} \\
\hline $1 \mathrm{~m}$ & $-3.6 \pm 0.0$ & $-2.6 \pm 0.2$ & $-2.1 \pm 0.4$ & $-2.9 \pm 0.2$ & $-2.6 \pm 0.0$ & $-2.1 \pm 0.0$ \\
\hline $3 \mathrm{~m}$ & $-1.6 \pm 0.2$ & $-2.6 \pm 0.0$ & $-1.4 \pm 0.0$ & $-2.1 \pm 0.0$ & $-1.5 \pm 0.1$ & $-2.0 \pm 0.1$ \\
\hline $4 m$ & $-5.6 \pm 0.7$ & $-32.6 \pm 0.1$ & $-5.6 \pm 0.4$ & $-28.6 \pm 0.7$ & $-8.1 \pm 2.0$ & $-27.1 \pm 1.1$ \\
\hline \multicolumn{7}{|c|}{ PDI } \\
\hline $1 \mathrm{~m}$ & $0.2 \pm 0.0$ & $0.2 \pm 0.0$ & $0.3 \pm 0.0$ & $0.3 \pm 0.0$ & $0.4 \pm 0.1$ & $0.4 \pm 0.0$ \\
\hline $3 \mathrm{~m}$ & $0.2 \pm 0.0$ & $0.2 \pm 0.0$ & $0.3 \pm 0.0$ & $0.3 \pm 0.0$ & $0.3 \pm 0.0$ & $0.3 \pm 0.0$ \\
\hline $4 \mathrm{~m}$ & $0.4 \pm 0.0$ & $0.5 \pm 0.2$ & $0.3 \pm 0.0$ & $0.2 \pm 0.0$ & $0.3 \pm 0.0$ & $0.3 \pm 0.0$ \\
\hline
\end{tabular}




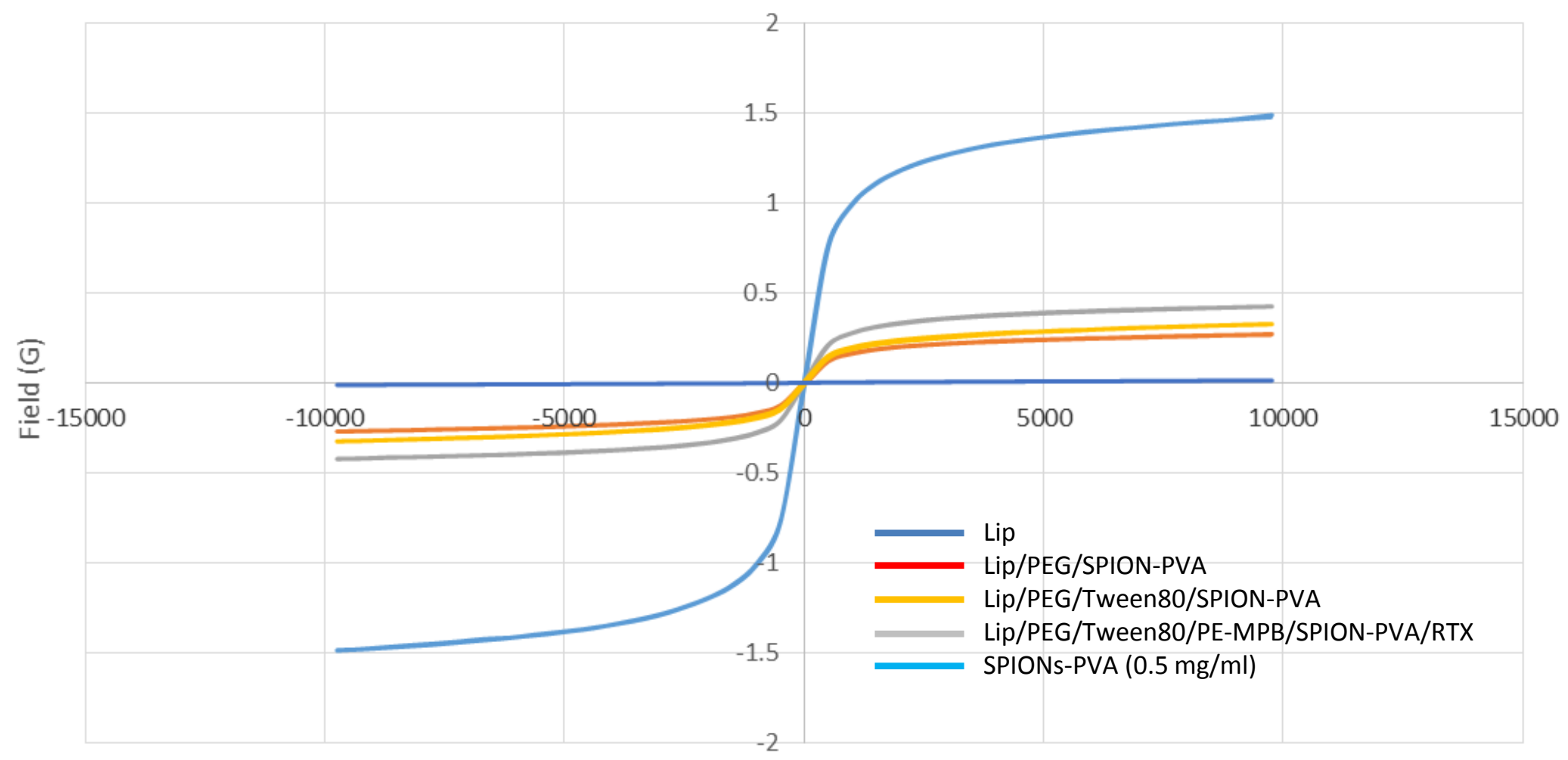

\begin{tabular}{|l|c|}
\hline \multicolumn{1}{|c|}{ samples } & Saturation magnetization (emu/g) \\
\hline Lip & 0.0 \\
\hline Lip/PEG/SPIONs-PVA & 0.3 \\
\hline Lip/PEG/Tween80/SPIONs-PVA & 0.3 \\
\hline Lip/PEG/Tween80/SPIONs-PVA/Rituximab & 0.4 \\
\hline SPIONs-PVA (0.5 mg/ml) & 1.5 \\
\hline Naked SPIONs & 28.9 \\
\hline
\end{tabular}


Fig. 4a

Lip/PEG/Tween80/SPIONs-PVA

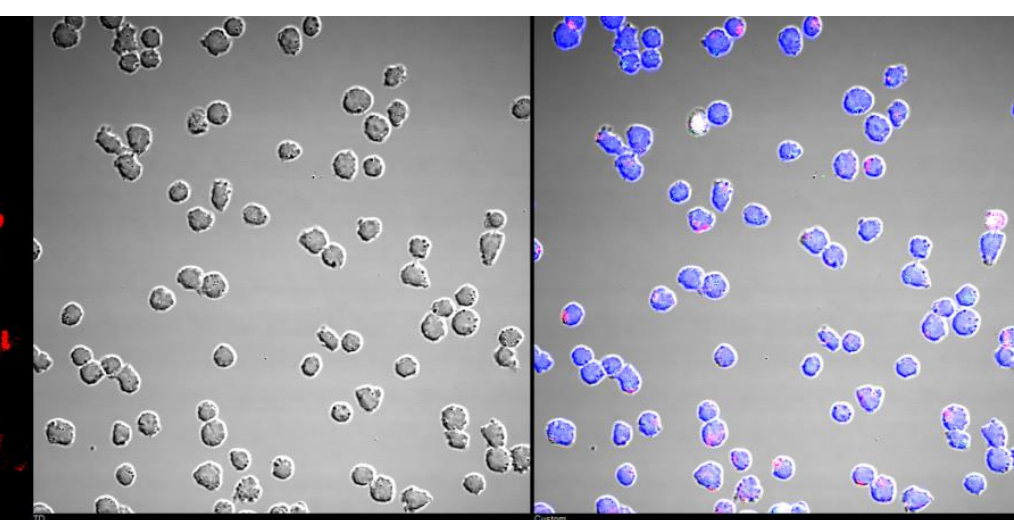

\section{Lip/PEG/Tween80/SPIONs-PVA/Rituximab}
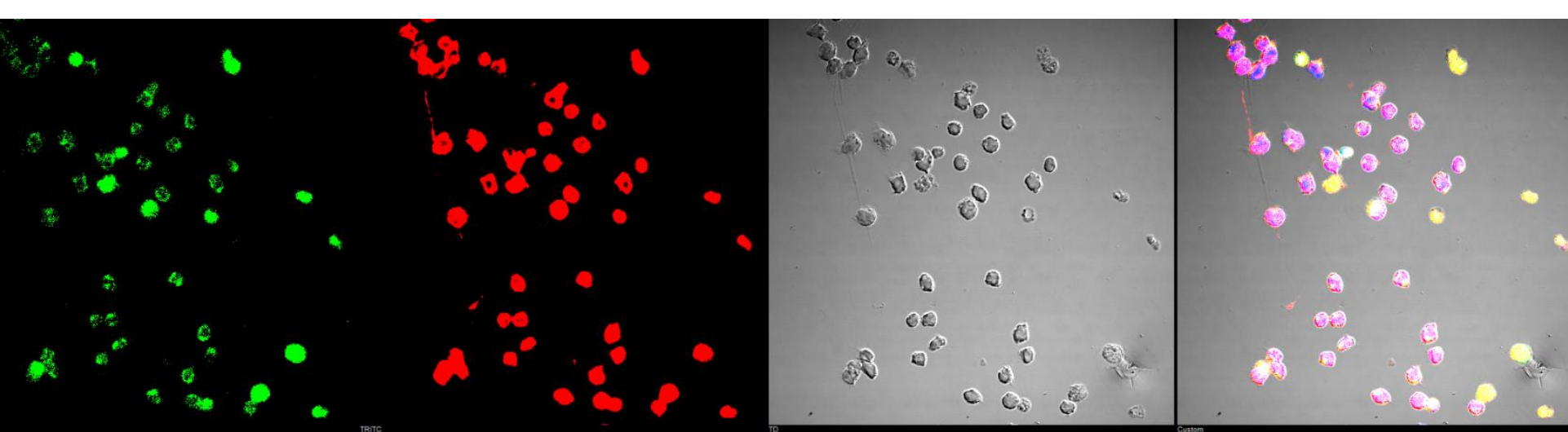
Fig. 4b

Granta Lip/PEG/Tween80/SPIONs-PVA

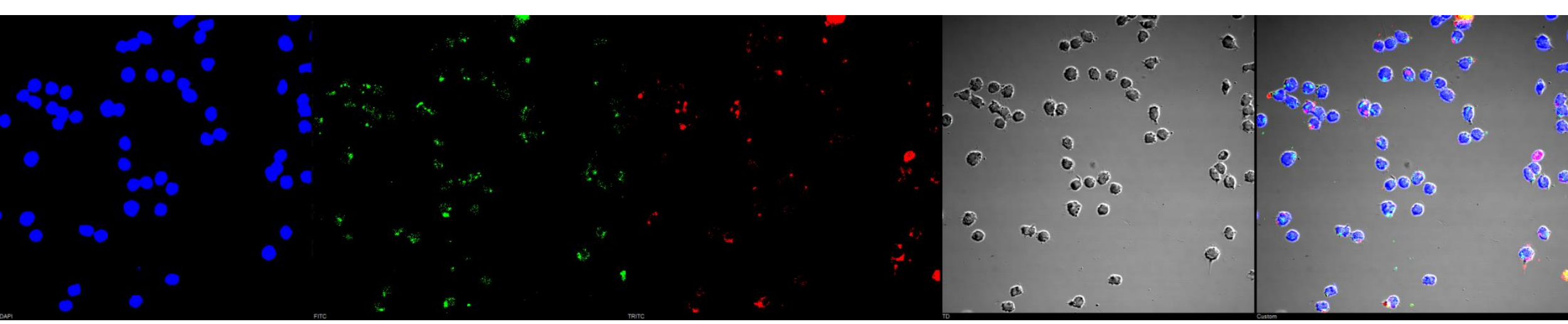

Lip/PEG/Tween80/SPIONs-PVA/Rituximab

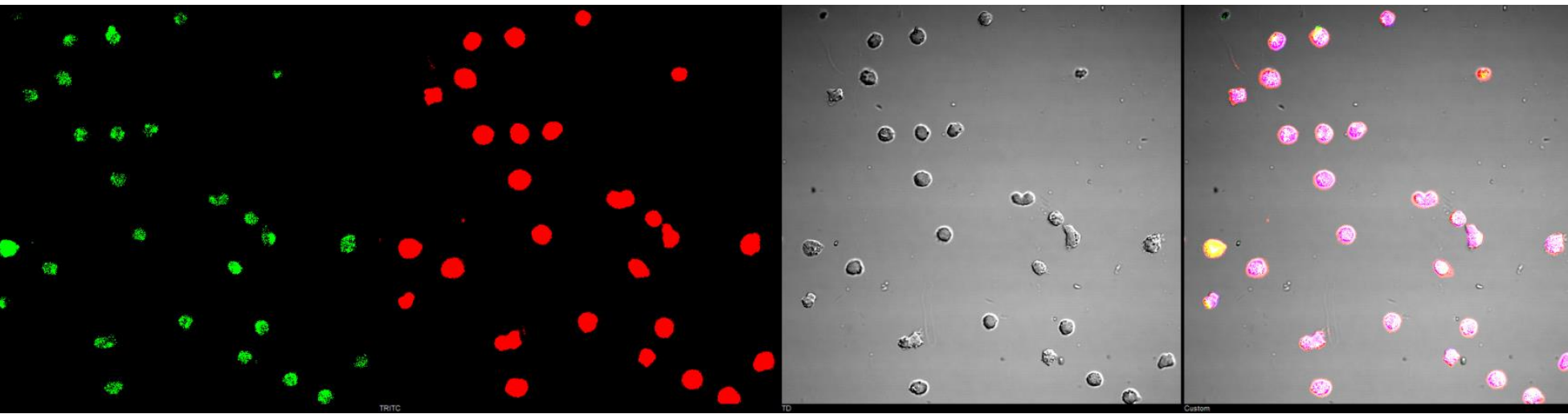




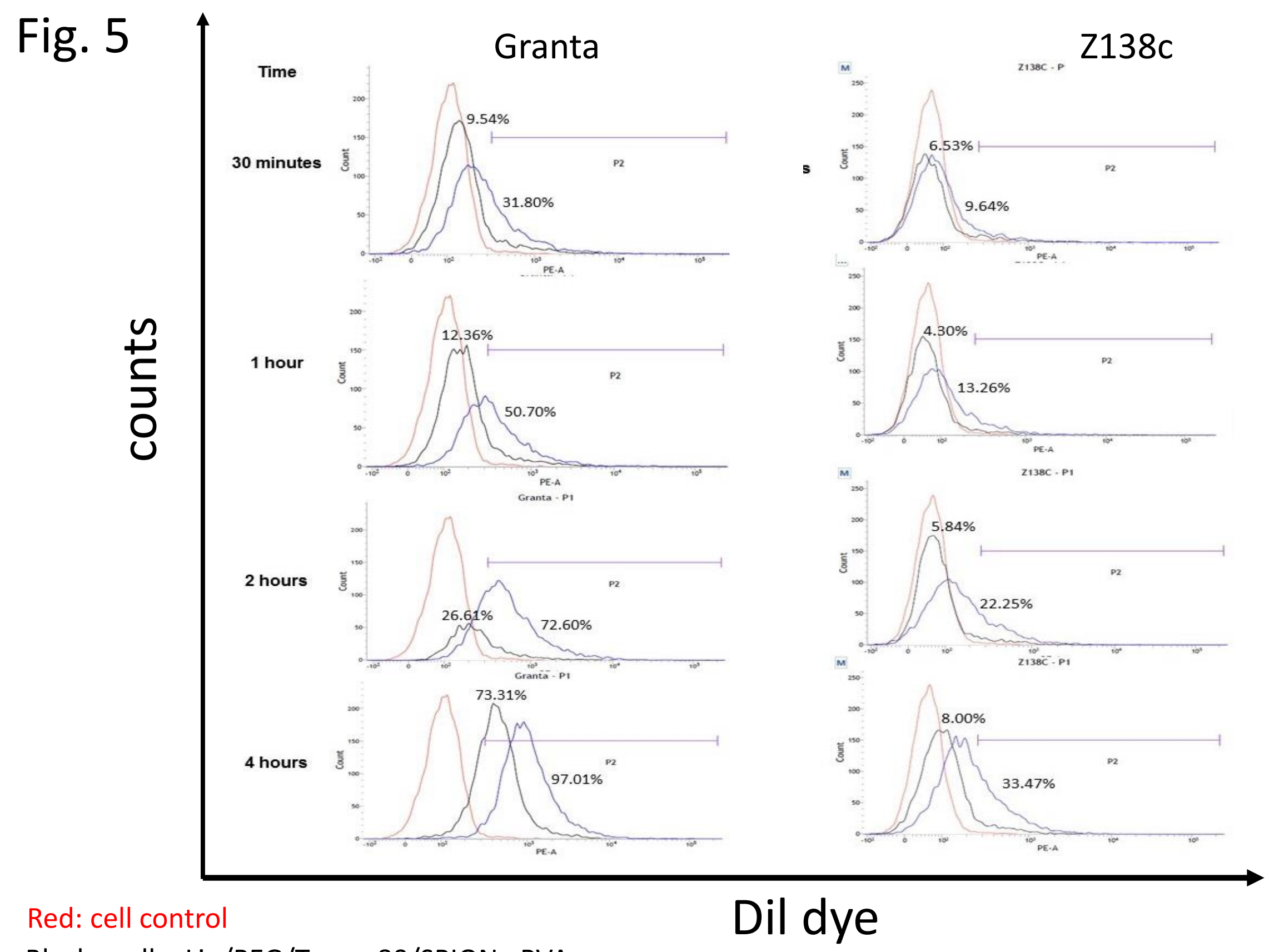

Black: cell + Lip/PEG/Tween80/SPIONs-PVA

Blue: cell +Lip/PEG/Tween80/SPIONs-PVA/RTX 
Fig. 6a

Granta

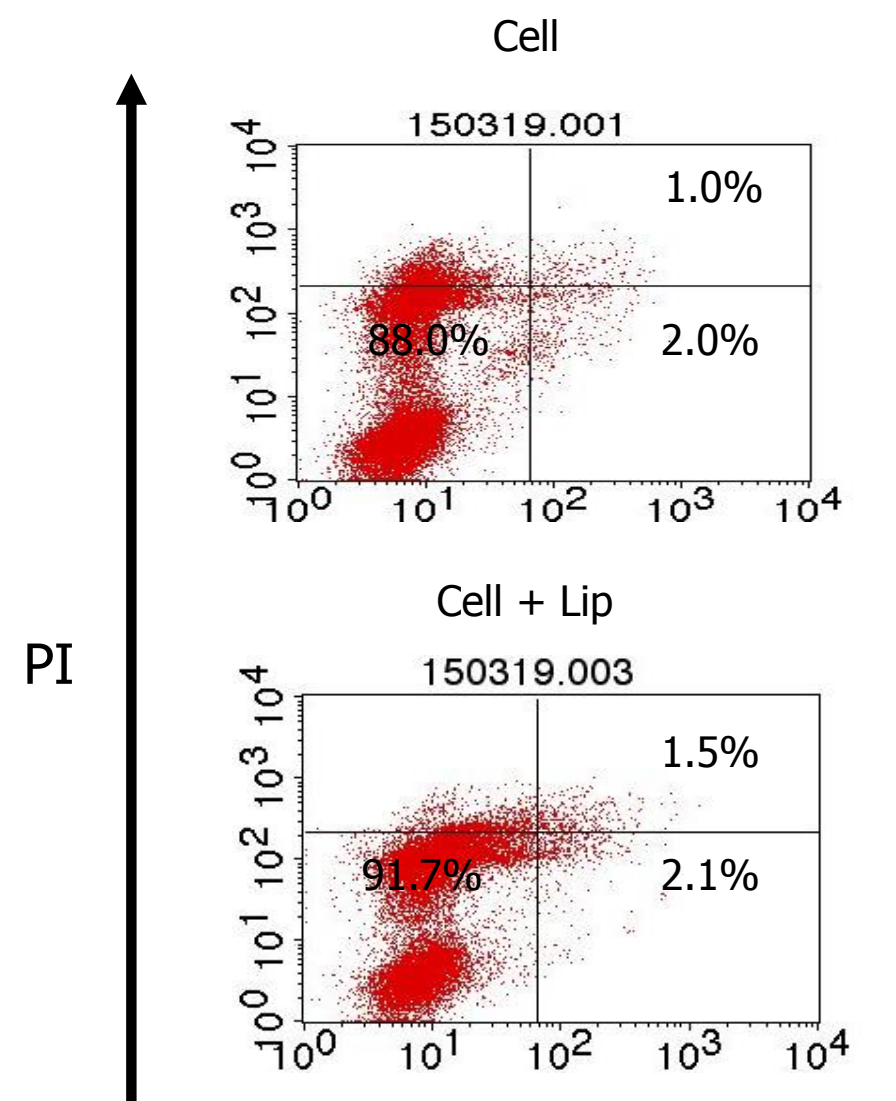

Cell + Rituximab

Granta

Cell + Lip/PEG/Tween80/SPIONs-PVA

Cell + Lip/PEG/Tween80/SPIONs-PVA/Rituximab
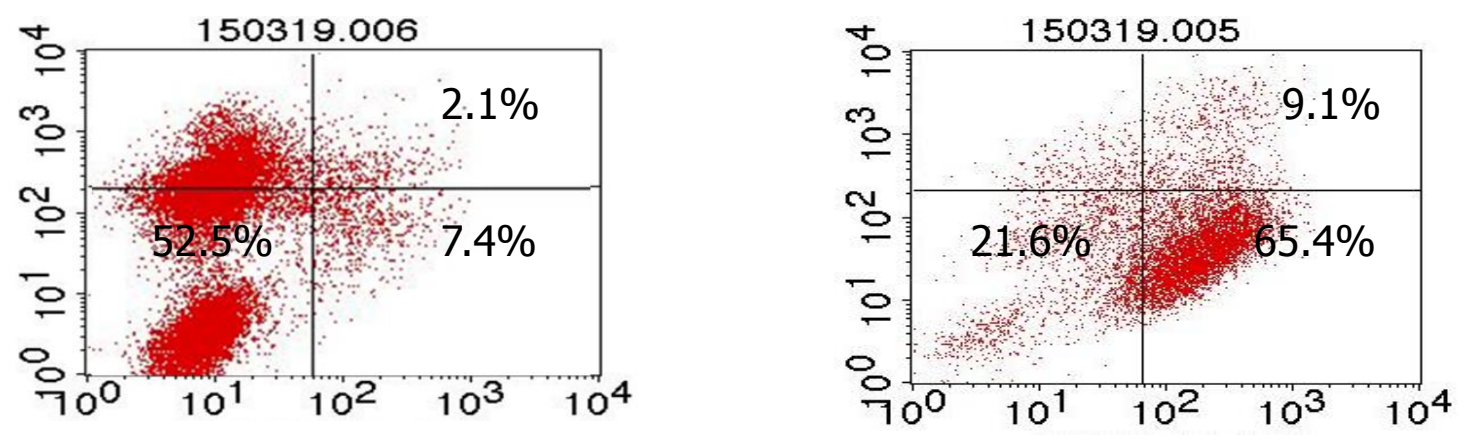

Annexin V-FITC

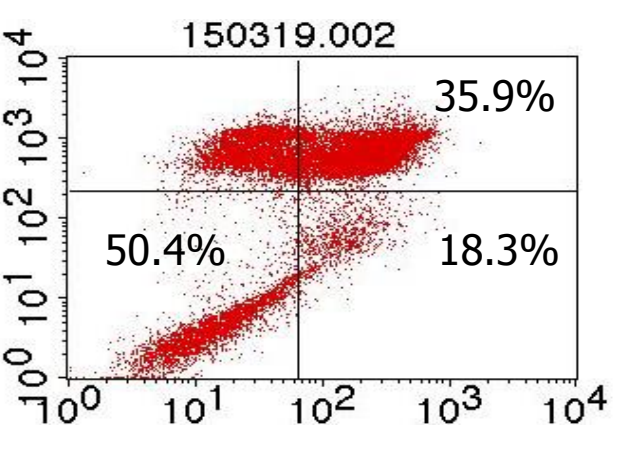

Cell + Lip/PEG/SPIONs-PVA

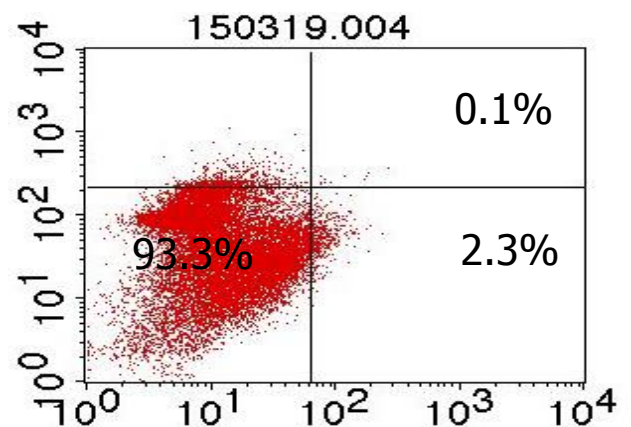


Fig. 6b

Z138c

Cell

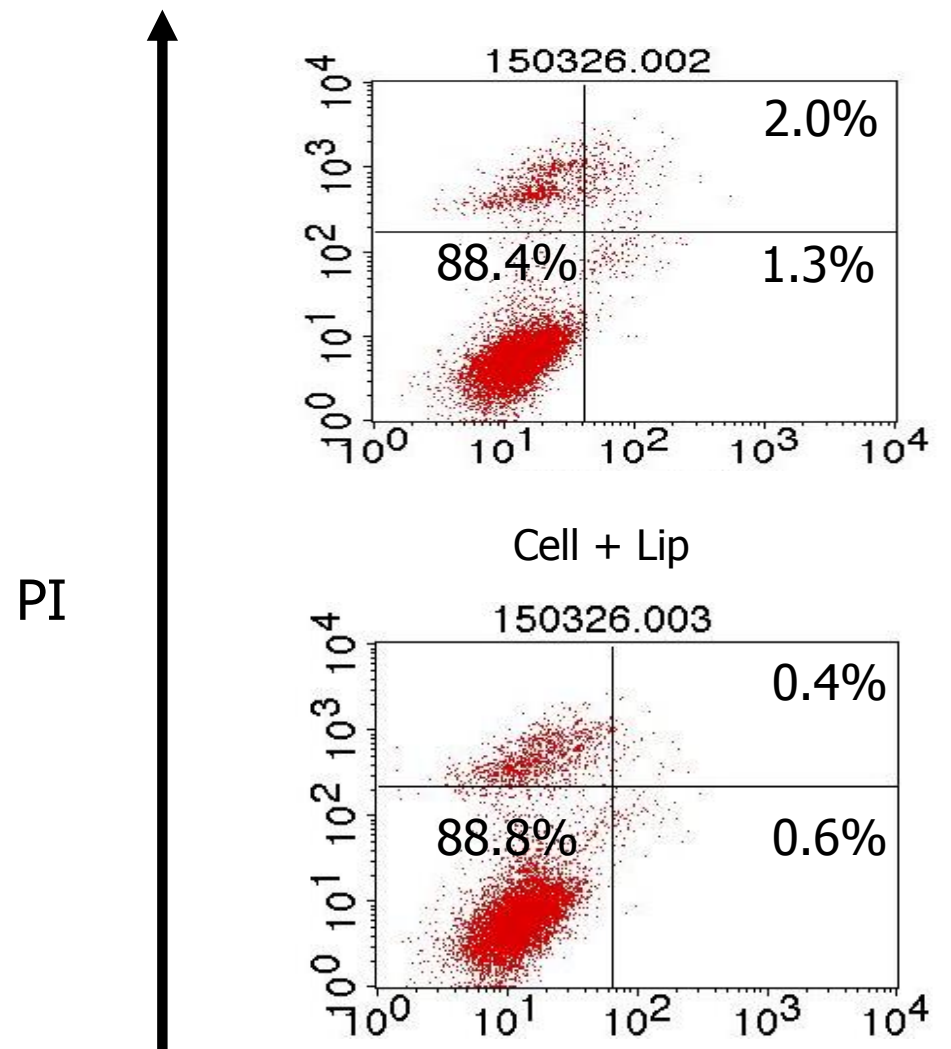

Cell + Rituximab

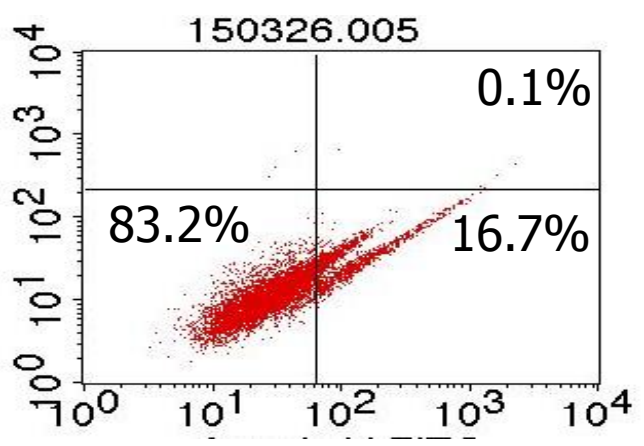

Cell + Lip/PEG/SPIONs-PVA

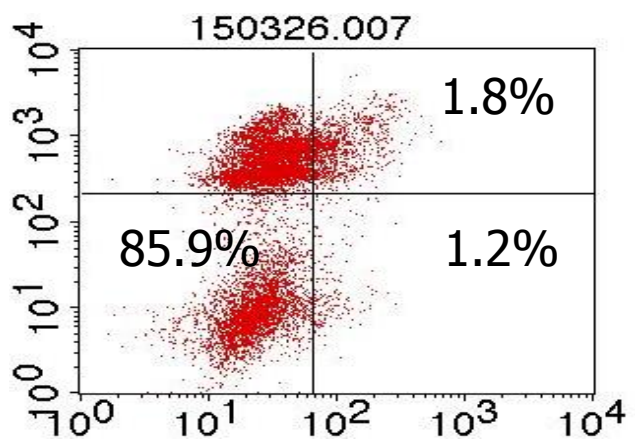

Cell + Lip/PEG/Tween80/SPIONs-PVA Cell + Lip/PEG/Tween80/SPIONs-PVA/Rituximab
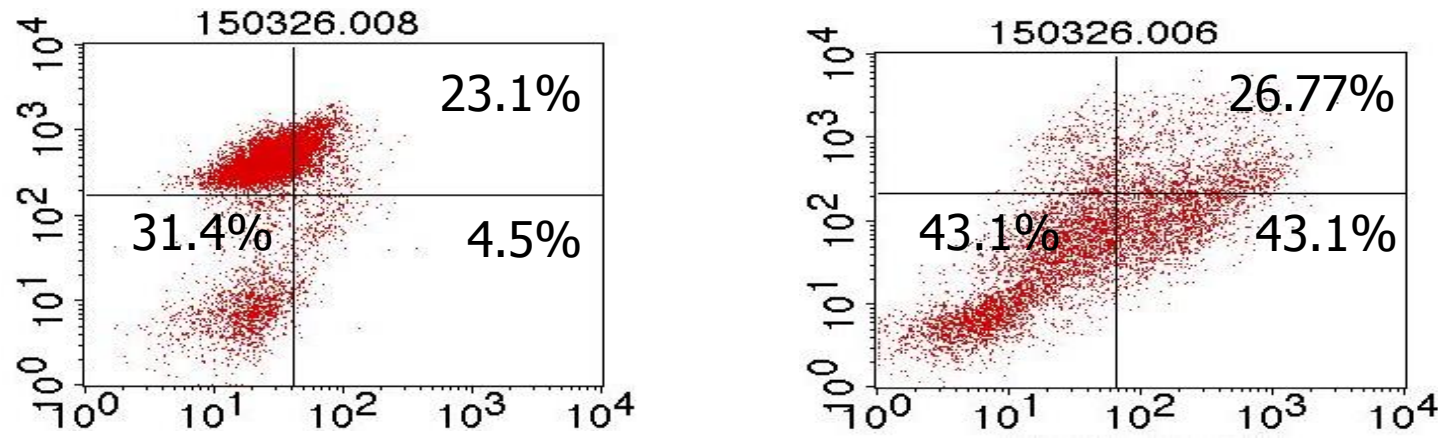
Fig. 7

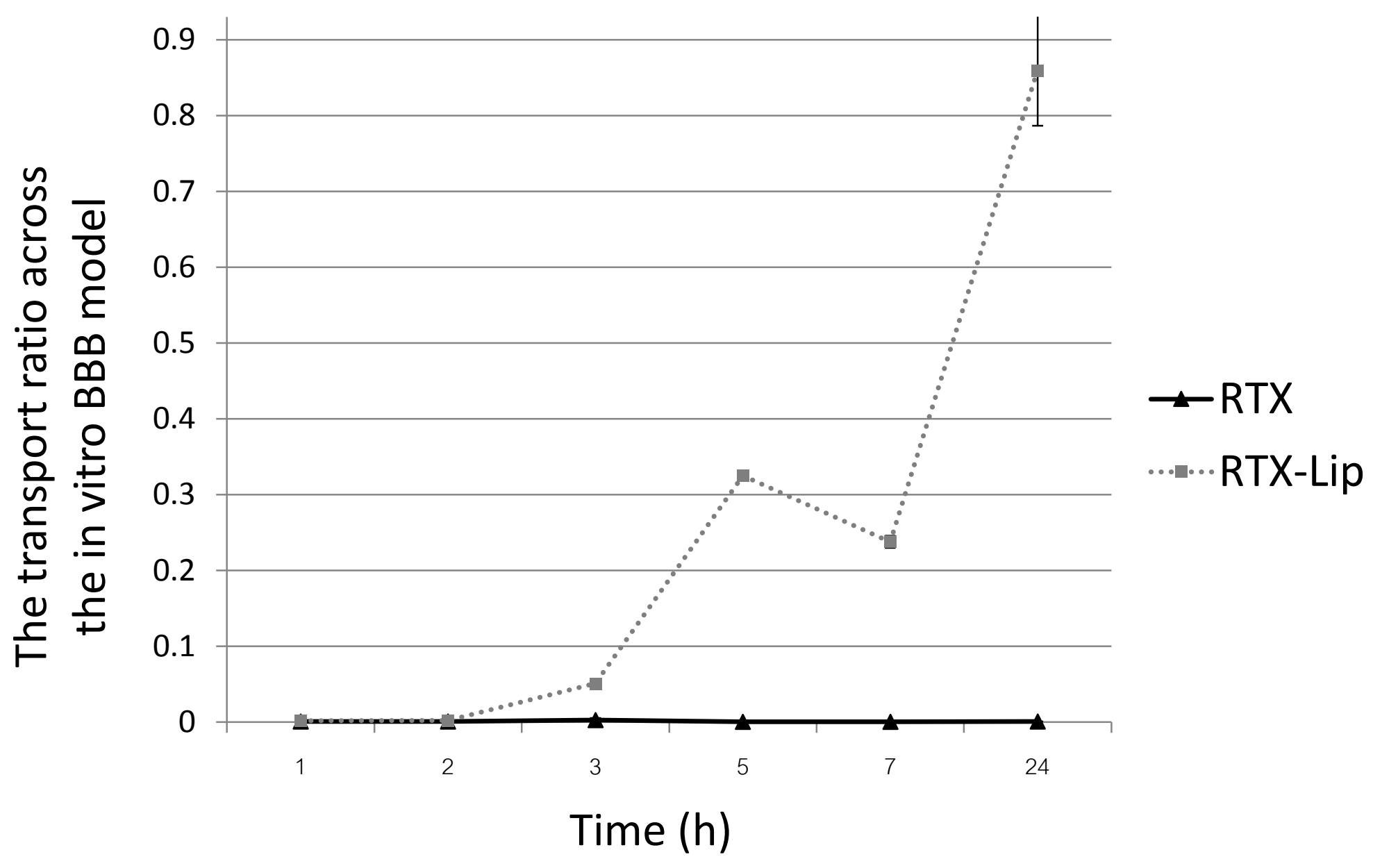


Fig. 8

\section{Therapeutic effect}

140

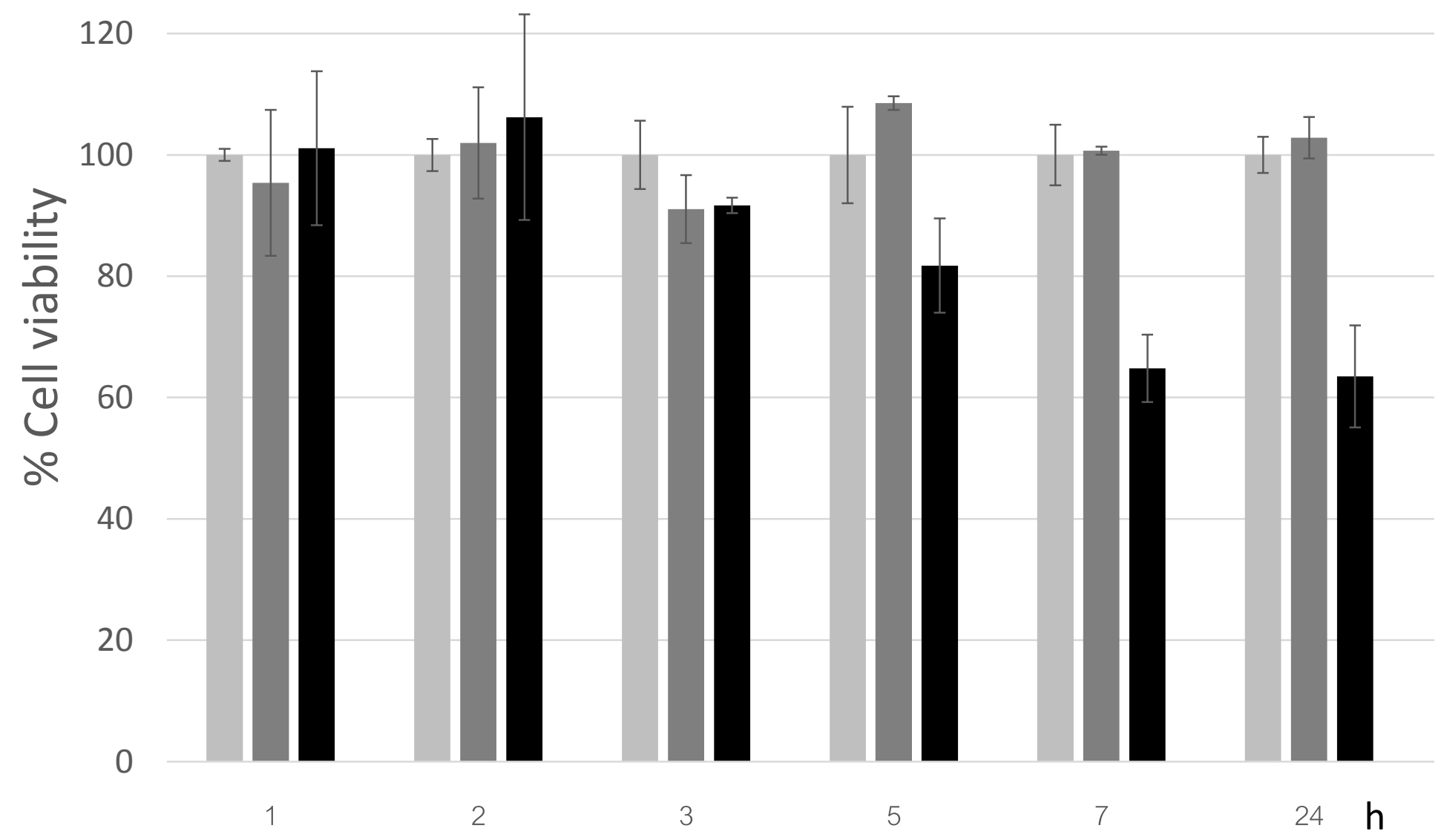

- Cell control Cell+Rituximab Cell+Lip/PEG/Tween80/SPIONs-PVA/Rituximab 